\title{
Farklı sulama seviyelerinin rezene (Foeniculum vulgare Mill) bitkisinde verim ve verim unsurları ile su kullanımına etkisi
}

\section{Effect of different 1rrigation levels on yield, yield components and water use in fennel (Foeniculum vulgare Mill)}

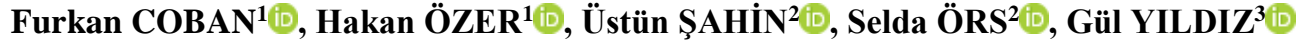 \\ ${ }^{1}$ Atatürk Üniversitesi, Ziraat Fakültesi, Tarla Bitkileri Bölümü, Erzurum \\ ${ }^{2}$ Atatürk Üniversitesi, Ziraat Fakültesi, Tarımsal Yapılar ve Sulama Bölümü, Erzurum \\ ${ }^{3}$ Kuzeydoğu Anadolu Kalkınma Ajansı, Erzurum \\ Sorumlu yazar (Corresponding author): F. Coban, e-posta (e-mail): furkan.coban@atauni.edu.tr \\ Yazar(lar) e-posta (Author e-mail): haozer@atauni.edu.tr, ussahin@atauni.edu.tr, seldaors@atauni.edu.tr,gul.yildiz@dap.gov.tr
}

\section{MAKALE BILLGISİ}

Alınış tarihi 02 Mart 2019

Düzeltilme tarihi 03 Mayıs 2019

Kabul tarihi 22 Mayıs 2019

Anahtar Kelimeler:

Rezene

Su kısitı

Tohum verimi

Verim unsurları

\begin{abstract}
ÖZ
Kısıntılı sulama, sınırlı su kaynaklarına sahip kurak ve yarı kurak bölgelerde su tasarrufu sağlamak için uygulanan genel bir stratejidir. Bu araştırma 2014 yılında Erzurum ekolojik koşullarında farklı sulama miktarlarının bitki boyu, dal sayısı, şemsiye sayısı, 1000 meyve ağırlığı ve rezene tohum verimi üzerindeki etkilerini belirlemek amacıyla yapılmıştır. Çalışmada dört farklı sulama suyu seviyesi $(\% 100,80,60$ ve 40$)$ uygulanmıștır. Sulama miktarları A sınıfı kap buharlaşması dikkate alınarak belirlenmiștir. Uygulamalar, üç tekerrürlü şansa bağlı deneme desenine göre düzenlenmiştir. İncelenen parametrelerde önemli farklılıklar gözlenmiștir. Genel olarak, artan su kısıtı seviyeleri, tohum verimini düşürmüștür ve en yüksek verim, en yüksek su seviyesinin uygulandığı parsellerden elde edilmiştir. Su kaynaklarının verimli kullanılması açısından buharlaşmanın \%80 düzeyinde sulamanın daha uygun olacağı sonucuna varılmıştır.
\end{abstract}

\section{ARTICLE INFO}

Received 02 March 2019

Received in revised form 03 May 2019

Accepted 22 May 2019

\section{Keywords:}

Fennel

Water deficit

Seed yield

Yield components

\begin{abstract}
Deficit irrigation is a general strategy applied for the saving of water in arid and semi-arid regions with limited water resources. This research was carried out in 2014 in Erzurum ecological conditions in order to determine the impacts of different irrigations quantities on the plant height, the number of branches, the number of umbrella, 1000-fruit weight and seed yield of fennel (Foeniculum vulgare Mill). The study included four different irrigation levels $(100 \%, 80,60$ and 40). Different irrigation levels were adjusted considering the evaporation from a Class A pan located at experiment field. Treatments were arranged in a randomized complete block design with three replicates. Significant differences have been observed in the parameters investigated. In general, the increasing water shortage levels have reduced seed yield and the highest yield was obtained from the plots where the highest water level is applied. In terms of the efficient use of water resources, it was concluded that irrigation application would be more appropriate for $80 \%$ of the evaporation.
\end{abstract}

\section{Giriş}

Rezene (Foeniculum vulgare) dünya çapında önemli bir tıbbi ve aromatik bitkidir. Umbelliferae familyasına dâhil olan rezene doğal olarak Akdeniz iklim kuşağının bitkisi olmasına rağmen, birçok bölgede ortaya çıkmış ve kültüre alınmıştır (Damjanović ve ark. 2005). Rezene Türkiye' de kuzey, güney ve batı bölgelerinde doğal olarak yetişen bir baharat ve ilaç bitkisidir (Özkan 1999).

Ülkemizde bölgelere göre "meyane, rezane, raziyane" gibi adlarla da tanınan rezene (Karaca 1998), tıbbi ve aromatik bitki olarak eski çağlardan beri bilinmektedir. Genellikle salatalarda, ekmekte, çeşitli likörlerde ve peynirlerde kullanılır (Damjanović ve ark. 2005). Sebze veya çeşni olarak tüketiminin yanı sıra sıvı ekstraktları (kök ve tohum) şekerleme endüstrisinde ve alkolsüz içeceklerde de kullanılmaktadır (Miraldi 1999; Arabacı ve Bayram 2005).

Rezenenin esas kullanılan kısmı kurutulmuş tohumlarıdır. İlaç ve baharat sanayisinde kullanımının yanı sıra bitkisel çay olarak da tüketilmektedir. Halk arasında mide rahatsızlıklarında 
gaz söktürücü olarak kullanılmaktadır. Ayrıca süt artıcı etkisi sayesinde kadınlar tarafından yaprağ 1 oldukça sık tüketilmektedir (Kaur ve Arora 2010).

Sınırlı su kaynaklarına sahip kurak ve yarı kurak bölgelerde kısıntılı sulama, su tasarrufu için uygulanan genel bir stratejidir. $\mathrm{Su}$ eksikliği koşullarında biyokütle üretiminde bir düşüş ile verimde bir azalma ortaya çıkmaktadır. Bununla birlikte, kısıntılı sulama uygulamalarının birçok bitkide su verimliliğini ve ayrıca çiftçilerin net gelirini arttırdığı bilinmektedir (Fereres ve Soriano 2007). Kısıntılı sulama uygulamaları bitkisel üretim yanında ürün kalitesini de önemli düzeylerde etkiyebilmektedir. Askari ve Ehsanzadeh (2015) ve Chiyaneh ve ark. (2016) su kısıntısının rezene fizyolojisine yönelik parametreler üzerinde önemli değişimler sağladığını gözlemlemişlerdir. Nourimand ve ark. (2012) rezene bitki ağırlıklarında kuraklık stresi altında önemli azalmalar belirlemişlerdir.

Sıcaklık, bitkisel üretiminde en önemli iklim faktörlerinden biridir. Fotosentez, solunum, transpirasyon, bitki fenolojisi ve sonuçta verim sıcaklık ile önemli derecede etkilenebilir (White ve Howden 2010; Hasanuzzaman ve ark. 2013). Sicaklık ve fotosentez arasında pozitif bir ilişki vardır (Hasanuzzaman ve ark. 2013). Dolayısıyla fotosentez, yüksekliğin artması ile birlikte genellikle sıcaklığın azaldığı yüksek rakımlı bölgelerde önemli seviyelerde etkilenebilir. Ayrıca, kuraklık stresi de fotosentezde önemli düşüşlere neden olmaktadır (Askari ve Ehsanzadeh 2015).

Yüksek rakımlı bölgelerde sıcaklık düşmekte, vejetasyon periyodu kısalmakta ve bu durum bitkinin verimi üzerine olumsuz etki yapmaktadır. Rezenede sulama çalışması çok fazla olmamakla birlikte yapılan çalışmalarda genelde rezenenin ihtiyaçlarına uygun sıcaklığın yeterli olduğu düşük rakımlı alanlarda yapılmıştır.

Genel olarak, bitkilerde su stresi verim ve kaliteyi önemli ölçüde etkilemektedir. Aynı zamanda yüksek rakımlarda bitki fizyolojisinde de önemli değişimler olabilmektedir. Bu çalışma farklı sulama seviyelerinin yüksek rakımlı yarı-kurak bir bölgede rezene bitkisinde verim ve verim unsurları üzerine etkilerini belirlemek amacıyla yürütülmüştür.

\section{Materyal ve Metot}

Araştırma Atatürk Üniversitesi Ziraat Fakültesi Tarımsal Araştırma ve Yayım Merkezi Müdürlüğüne ait deneme alanında 2014 yılında yaklaşı $1800 \mathrm{~m}$ yükseltide yürütülmüştür. Denemede Burdur ilinden temin edilen rezene popülasyonu kullanılmıştır. Çalışmada A sınıfı buharlaşma kabından oluşan kümülatif buharlaşma değerlerinin $(50 \pm 15 \mathrm{~mm})$ dört farklı bitkikap katsayısıyla (Kcp) $(1,0 ; 0,80 ; 0,60 ; 0,40)$ düzeltilmesiyle elde edilen miktarlardaki su, farklı sulama suyu düzeyleri olarak rezene bitkisine uygulanmıştır. A sınıfi kabın kurulması ve işletilmesinde Allen ve ark. (1998)'daki yaklaşımlar dikkate alınmıştır.

Erzurum'da yaz ayları oldukça serin geçmektedir. Uzun yıllar ve denemenin yapıldığı yıla ait mayıs-ekim ayları arasındaki bitki gelişme periyoduna ait sıcaklık ortalamaları sırası ile 14.2 ve $16.1 C^{\circ}$ olmuştur. Deneme y1lında en yüksek sıcaklık ağustos $\left(22.2 \mathrm{C}^{\circ}\right)$ ayında, en düşük sıcaklık ise ekim $\left(9.2 \mathrm{C}^{\circ}\right)$ ayında kaydedilmiştir. Yetișme dönemi boyunca 270 mm yağış ölçülmüş ve bu yağış miktarı 25 yıllık ortalamanın (208.7 mm) üzerinde olmuştur. Yağışın önemli bir miktarı $(109.4 \mathrm{~mm})$ rezene bitkisinin çimlenme periyodu olan Mayıs ayında gerçekleşmiştir.
Uzun yıllar ortalamasına göre mayıs-ekim dönemindeki aylık ortalama nispi nem $\% 57.5$, denemenin yürütüldüğü ayların ortalamasında ise nispi nem \%52.4 olmuştur. Nispi nem değeri, deneme yılının mayıs ayından (\%65.4) ağustos ayına (\%37.2) kadar azalmış, eylül $(\% 48.3)$ ve ekim aylarında (\%68.9) tekrar artmıştır.

Drenaj problemi olmayan deneme sahası toprakları US toprak sınıflamasına göre Aridisol'dur (Soil Survey Staff 1992). Denemeler öncesi $60 \mathrm{~cm}$ derinliği temsilen alınan örneklerde Klute (1986) ve Page ve ark. (1982) belirtilen yöntemler kullanılarak bazı temel toprak özellikler belirlenmiştir. Tın bünyeli toprağın $\mathrm{pH}$ ve elektriksel iletkenlik değeri ile organik madde, $\mathrm{CaCO}_{3}$, toplam $\mathrm{N}, \mathrm{P}_{2} \mathrm{O}_{5}$ ve $\mathrm{K}_{2} \mathrm{O}$ içerikleri için ortalama değerler sırasıyla 7.50, $1.21 \mathrm{dS} \mathrm{m}^{-1}, \% 0.60, \% 1.42, \% 0.07,6.80$ $\mathrm{kg} \mathrm{da}^{-1}$ ve $23.6 \mathrm{~kg} \mathrm{da}^{-1}$ olarak belirlenmiştir.

Deneme "Şansa Bağlı Tam Bloklar Deneme" deseninde 3 tekerrürlü olarak kurulmuştur. Deneme parselleri $5 \mathrm{~m}$ uzunluğunda, $1.2 \mathrm{~m}$ genişliğinde 4 sıradan oluşmuştur. Parseller arasında $0,8 \mathrm{~m}$, bloklar arasında $2 \mathrm{~m}$ aralık bırakılmıştır. Ekim işlemi 6 mayıs tarihinde dekara $2.5 \mathrm{~kg}$ tohum kullanılarak gerçekleștirilmiştir. Araştırmada gübre olarak amonyum sülfat (\%21) ve triple süperfosfat $\left(\% 46 \mathrm{P}_{2} \mathrm{O}_{5}\right)$ kullanılmıştır. Parsellere dekara $5 \mathrm{~kg} \mathrm{da}^{-1} \mathrm{P}_{2} \mathrm{O}_{5}$ hesabiyla fosforlu gübre ve $7 \mathrm{~kg} \mathrm{da}^{-1}$ azot dozları serpme olarak verilip, ekim öncesi diskaro ile toprağa karıştırılmıştır. Yetişme mevsimi boyunca yabancı otlarla çapalamayla, hastalık ve zararlılarla ilaçlama yapılarak mücadele edilmiştir.

Sulama suyunun uygulanmasında damla sulama yöntemi kullanılmıştır. Damla sulama sistemi kontrol ünitesi ve boru hatlarından oluşturulmuştur. İki bitki sırasına bir yerleştirilmiş olan lateral borular 16 mm'lik PE malzemeden olup, damlatıc1 aralığı $25 \mathrm{~cm}$ olarak seçilmiştir. Damlatıcılar in-line tipli 1 atm'lik işletme basıncında $4.81 \mathrm{~h}^{-1}$ debi sağlamaktadır. Sulama suyu olarak tuzluluk ve sodyumluluk problemi olmayan $(\mathrm{pH}$; 7.45 , elektriksel iletkenlik; $0.295 \mathrm{dS} \mathrm{m}^{-1}$, sodyum adsorbsiyon oranı; 0.48) havuzda dinlendirilmiş yer altı suyu kullanılmıştır. Parsellere uygulanan su sayaçla ölçülerek kayıt altına alınmıştır.

Konulara uygulanacak sulama suyu aşağıdaki eşitlikle hesaplanmıştır (Ertek 2011).

$$
\begin{aligned}
& \mathrm{d}=\text { Epan } \times \mathrm{Kcp} \times \mathrm{P} \\
& \mathrm{P}=\mathrm{Wb} / \mathrm{Ws}
\end{aligned}
$$

Burada; d: sulama suyu miktarı (mm), Epan: iki sulama arasında kümülatif A sınıfı kap buharlaşması (mm), Kcp: bitkikap katsayıs1, P: bitki örtü oranı, Wb: bitki örtü genişliği $(\mathrm{cm})$ ve Ws: bitki sıra aralığıdır (cm). Kcp katsayıları $S_{1}, S_{2}, S_{3}$ ve $S_{4}$ sulama konuları için sırasıyla $1.0,0.80,0.60$ ve 0.40 olarak alınmıştır. Bitki örtü oranı minimum 0.30 alınmış bitki büyümesiyle artırılmış 0.80 ' de sabitlenmiştir.

Araştırmada gözlem, ölçüm ve değerlendirmeler kenarlardan birer sıra ve ortadaki iki sıranın da uç kısımlarından 25 'er $\mathrm{cm}$ kenar tesiri olarak birakıldıktan sonra geriye kalan kısımlarda yapılmıştır. Hasat olgunluğu kriteri olarak meyvelerin henüz yeni kahverengileşmeye başladığ dönem esas alınmıştır. Olgunlaşma zamanlarına göre hasat 1 Ekim- 4 Ekim arasında elle yapılmıştır. Daha sonra hasat edilen bitkiler kurutulmaya bırakılmış ve kuruma tamamlandıktan sonra harman edilerek tohumlar çıkarılmıştır. Sulama verimliliğini değerlendirmek için rezenenin tohum verimleri $\left(\mathrm{kg} \mathrm{da}^{-1}\right)$ sulama 
suyu miktarına $(\mathrm{mm})$ oranlanarak sulama suyu kullanım etkinlikleri (IWUE) $\left(\mathrm{kg} \mathrm{m}^{-3}\right.$ ) hesaplanmıştır (Howell 2001).

Bitki verileri ile IWUE değerleri SPSS paket programı yardımıyla varyans (ANOVA) analizine tabi tutulmuş, önemli ortalamalar Duncan çoklu karşılaştırma testiyle sınıflandırılmıştır. Ayrıca regresyon tekniği kullanılarak suverim ilişkileri analiz edilmiştir.

\section{Bulgular ve Tartıșma}

\subsection{Sulama Miktar}

Yetiştirme periyodu (6 Mayıs - 4 Ekim) boyunca deneme alanına yerleştirilen A sınıfı buharlaşma kabında kümülatif buharlaşma miktarı $776.4 \mathrm{~mm}$ olarak ölçülmüştür (Şekil 1). 10 Haziran - 4 Eylül dönemini kapsayan sulama periyodunda $S_{1}$, $\mathrm{S}_{2}, \mathrm{~S}_{3}$ ve $\mathrm{S}_{4}$ konularına sirasiyla $300.5 \mathrm{~mm}, 247 \mathrm{~mm}, 193.5 \mathrm{~mm}$ ve $140 \mathrm{~mm}$ toplam sulama suyu uygulanmıştır. Haziran ayında tüm konulardaki bitkiler eşit su miktarlarıyla sulanmış, bu dönemde toplam $33 \mathrm{~mm}$ sulama suyu uygulanmıştır (Şekil 1). $\mathrm{S}_{1}, \mathrm{~S}_{2}, \mathrm{~S}_{3}$ ve $\mathrm{S}_{4}$ konularında sezonluk uygulanan sulama suyu miktarları buharlaşma miktarının sırasıyla \%38.7, 31.8, 24.9 ve 18.0' i kadar olmuştur. Solanki ve ark. (2017) tarafından yapılan bir çalışmada rezene bitkisinin su tüketimi yüzey sulamada yaklaşık $800 \mathrm{~mm}, 1.0,0.8$ ve 0.6 kap katsayılarıyla yapılan damla sulamada 770,705 ve $555 \mathrm{~mm}$ olarak bulunmuştur. Bu yüksek değerlerin çeşit ve bölge farkının etkisinin özel bir sonucu olarak ortaya çıktığı düşünülmüştür. Türkiye' de Sulanan Bitkilerin Su Tüketimi Rehberi (Anonymous 2016) değerleri incelendiğinde ise rezene bitkisi su tüketiminin 400$450 \mathrm{~mm}$ arasında değiştiği görülmüştür. $\mathrm{Bu}$ bulgulara göre çalışmamızda uygulanan sulama miktarlarının su tüketimi değerlerini aşmadığı anlaşılmıştır.

\subsection{Bitki Boyu}

Farkı sulama miktarları uygulanarak yetiştirilen rezene bitkisinde ortalama bitki boyları 45.6-58.9 cm arasında değişmiştir (Şekil 2a). En yüksek bitki boyu $\mathrm{S}_{1}$ uygulanmasında, en düşük ise $\mathrm{S}_{4}$ uygulamasında elde edilmiştir. Çalışmada sulama miktarları azaldıkça bitki boyunun azaldığı gözlemlenmiştir. İstatistiksel olarak sulama konuları arasındaki fark önemli çıkmasa da $\mathrm{S}_{4}$ konusu $\mathrm{S}_{1}$ 'e göre \%22.6'lık bir azalış göstermiş olup pratikte dikkate alınabilir bir değişim olarak değerlendirilebilir. Benzer durum Foenicum vulgare (Zardak ve ark. 2016), Parthenium argentatum (Nik ve ark. 2013), Thymus carmanicus (Bahreininejad ve ark. 2014), Salvia officinalis
(Bettaieb ve ark. 2009), Mentha pulegium (Hassanpour ve ark. 2014) gibi bitkilerde görülmüş ve su kısıtı bitki boyunda azalmaya neden olmuştur. Godara ve ark. (2013), daha iyi sulama koşullarının fotosentetik etkiden dolayı daha iyi vejetatif gelişme sağlayacağını ifade etmiştir.

\subsection{Dal Sayısı}

Dal sayısı 5.0-6.5 aralığında değişim göstermiş ve en yüksek dal sayısı en fazla sulanan parsellerden $\left(\mathrm{S}_{1}\right)$ elde edilmiştir (Şekil 2b). $S_{2}$ uygulaması $S_{1}$ uygulamasıyla benzer sonuç sağlamış ve bu iki konu aynı grupta yer alan $S_{3}$ ve $S_{4}$ uygulamalarından önemli düzeyde $(\mathrm{p}<0.01)$ farklı bulunmuştur. Sonuç olarak sulama miktarının azalmasıyla dal sayısı azalış göstermiștir. Nitekim en düşük dal sayısı an az sulanan parsellerden elde edilmiştir. Çalışmamızla uyumlu bir şekilde Ozturk ve ark. (2004), Melissa officinalis 'de yürütmüş oldukları çalışmada su kısıtı arttıkça dal sayısının azaldığını belirtmişlerdir.

\section{4. Şemsiye Sayısı}

Rezene bitkisinde şemsiye sayısı sulama miktarlarından önemli düzeyde $(\mathrm{p}<0.01)$ etkilenmiş ve $6.7^{-1} 0.5$ arasında değişim göstermiştir (Şekil 2c). En fazla şemsiye sayısı en fazla sulama suyu uygulanan $S_{1}$ parsellerinde, en düşük şemsiye sayısı ise en az sulanan $\mathrm{S}_{4}$ parsellerinden elde edilmiş $\mathrm{S}_{4}$ 'e göre \%36.2' lik bir azalışa yol açmıştır. Bettaieb ve ark. (2011), kimyonda şemsiye sayısının su kısıtı arttıkça azaldığını fakat sonra ki seviyelerinde kararsız bir eğilim gösterdiğini belirtmiştir. Benzer durum çalışmamızda da gözlemlenmiştir.

\subsection{0-meyve a $\breve{g} ı r l i \breve{g l}$}

Rezenede farklı su kısıtı uygulamalarının etkisi Şekil 2d' de gösterilmiştir. Bin meyve ağırlığı $8.31 \mathrm{~g}$ ile $9.85 \mathrm{~g}$ arasında değişmiştir. Sulama miktarı azaldıkça yani kısıt seviyeleri arttıkça bin meyve ağırlığında azalmaların olduğu belirlenmiş ve en yüksek bin meyve ağırlı̆ğ en fazla sulanan parsellerden elde edilmiştir. $\mathrm{S}_{4}$ konusunda azalma miktarı \%15.6' ya ulaşmıştır. Askari ve Ehsanzadeh (2015), rezene bitkisinde yürütmüş oldukları çalışmada su kısıtı arttıkça 1000-meyve ağırlığının azaldığı bildirmiştir. Ayrıca diğer bitkiler üzerinde yürütülen su stresi çalışmalarından Brassica napus L. bitkisinde bin tane ağırlığının su kısıtı artıkça azaldığı belirlenmiştir (Shiranirad ve Zandi 2012; Mirzaei ve ark. 2013). Yukarıda belirtilen çalışmalar çalışmamızla benzerlik göstermiştir.

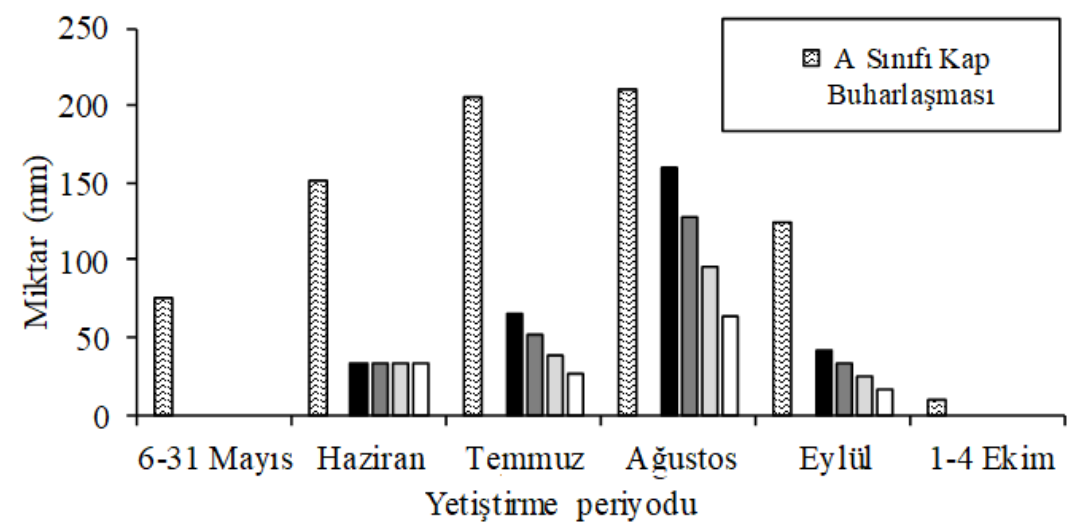

Şekil 1. Yetiştirme periyodu aylık buharlaşma ve sulama miktarları.

Figure 1. Monthly evaporation and irrigation quantities during the growing season. 

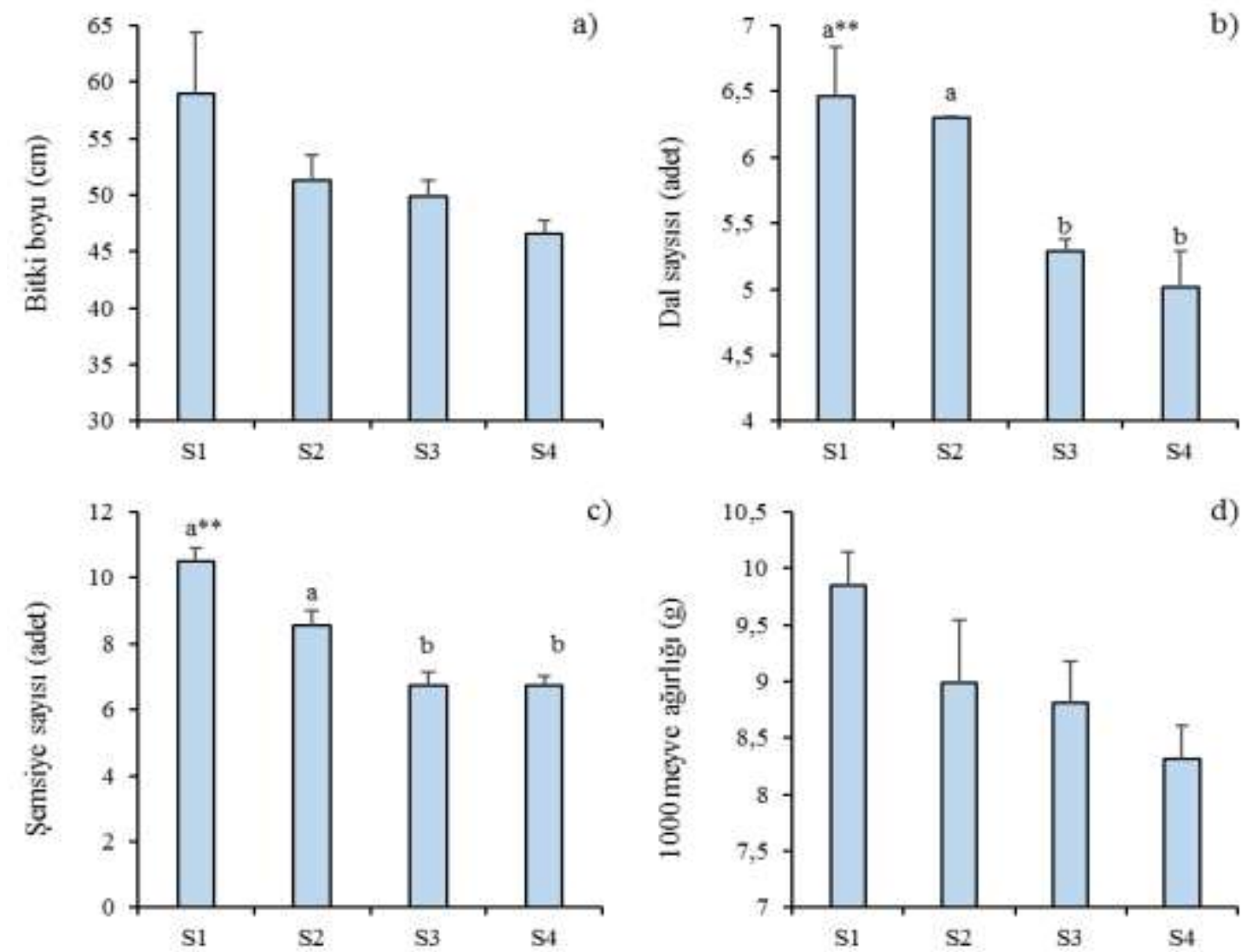

Şekil 2. Farklı sulama miktarlarının rezene bitkisinde a) bitki boyu b) dal sayısı c) şemsiye sayısı d) 1000-meyve ağırlı̆̆ üzerine etkileri. ** \%1 seviyesinde önemlidir.

Figure 2. Effect of different irrigation levels on the a) plant height b) branches plant ${ }^{-1}$ c) umbrella plant ${ }^{-1}$ d) 1000 -seed weight of fennel plant. ${ }^{* *}$ Significant at the 0.01 level.

\subsection{Tohum verimi $\left(\mathrm{kg} \mathrm{da}^{-1}\right)$}

Rezene bitkisi genel olarak tohumu için yetiştirilen ve suya olumlu tepki veren bir bitki olarak bilinmektedir. Çalışmamızda tohum veriminin $22.79 \mathrm{~kg} \mathrm{da}^{-1}$ ile $37.34 \mathrm{~kg} \mathrm{da}^{-1}$ arasinda değiştiği gözlemlenmiştir (Şekil 3). Tohum verimi sulama miktarlarından çok önemli düzeyde $(\mathrm{p}<0.01)$ etkilenmiştir. Azalan sulama miktarları tohum verimini azaltmış dolayısıyla en yüksek tohum verimi en fazla sulamanın yapıldı̆̆ 1 parsellerden elde edilmiştir.

En fazla su miktarıla sulama yapılan parsellerde tohum verimi, en az su miktarıyla sulanan parsellere göre \%63.8 daha fazla olmuştur. Uygulanan su miktarı ile tohum verimi arasında önemli $(p<0.01)$ doğrusal ilişki belirlenmiştir (Şekil 4). Benzer olarak, Semiz ve ark. (2012) tuzlu koşullar altında rezene bitkisinde evapotranspirasyon ile verim arasında önemli doğrusal bir ilişki belirlemiştir.

Rezene bitkisinde sulamayla tohum veriminin arttığ önceki çalışmalarla ortaya konmuştur (Jat ve ark. 2015; Meena ve ark. 2016). Benzer durum, kimyon (Seghatoleslami 2013), kişniş (Aliabadi ve ark. 2008; Angeli ve ark. 2016) ve anason (Aloghareh ve ark. 2013) bitkilerinde de gözlemlenmiştir. Öte yandan Zardak ve ark. (2016), tarafindan rezenede yürütülen çalışmada tohum verimi, kuraklık stresi uygulamalarına kararsız bir tepki göstermiş ve en yüksek tohum verimi orta düzeydeki kuraklık uygulamalarından elde edilmiştir. Genel olarak su kısıtı uygulamaları tohum verimi üzerine çiçeklenme döneminde, sapa kalkma dönemine göre daha fazla etki göstermektedir (El
Balla 2013). Benzer durum, meyvelerinden yararlanılan bitki olan rezene içinde geçerlidir. Su stresi, yaprakların gaz alışveriş özellikleri, asimilatların kaynaktan depoya taşınmasında ve kuru maddelerin generatif ve vejetatif bitki organları arasındaki paylaşımındaki bozulmalar nedeniyle tohum verimini azaltıcı etki göstermektedir (Zhou ve ark. 2013). Su stresi fotosentez kapasitesinin azalması, stomaların kapanması ve karbonhidrat miktarının azalması gibi fizyolojik durumlar sonucunda da potansiyel verimi azaltmaktadır (Flexas ve ark. 2013).

\subsection{Sulama Suyu Kullanım Etkinliği}

Birim suya karşı1ık alınan tohum verimi değişimini gösteren sulama suyu kullanım etkinliği (IWUE) $S_{1}$ uygulamasında en düşük $\left(0.124 \mathrm{~kg} \mathrm{~m}^{-3}\right)$ ve $\mathrm{S}_{4}$ uygulamasında en yüksek $(0.163$ $\mathrm{kg} \mathrm{m}^{-3}$ ) olarak belirlenmiş, uygulamalar arasında fark önemli bulunmuştur (Şekil 5). En az sulanan uygulama $\left(\mathrm{S}_{4}\right)$ en fazla sulanan uygulamaya göre IWUE' de \%31.5' lik bir artış belirlenmiştir. Benzer olarak Hassan ve Ali (2014), kişniş bitkisinde A sınıfı kap buharlaşma değerinin \%40‘ 1 düzeyinde damla sulama yöntemiyle sulama suyu uygulamasının en yüksek IWUE değerini verdiğini, en düşük değerin ise en fazla sulanan uygulamadan elde edildiğini ifade etmiştir.

Bulgularımıza göre, IWUE değerlerindeki artışın sulama miktarlarının azalmasından kaynaklandığı söylenebilir, çünkü IWUE değerleri ve sulama miktarları arasında, IWUE değerleri ile verim arasındakine kıyasla daha yüksek doğrusal korelasyon elde edilmiştir (Şekil 6). 


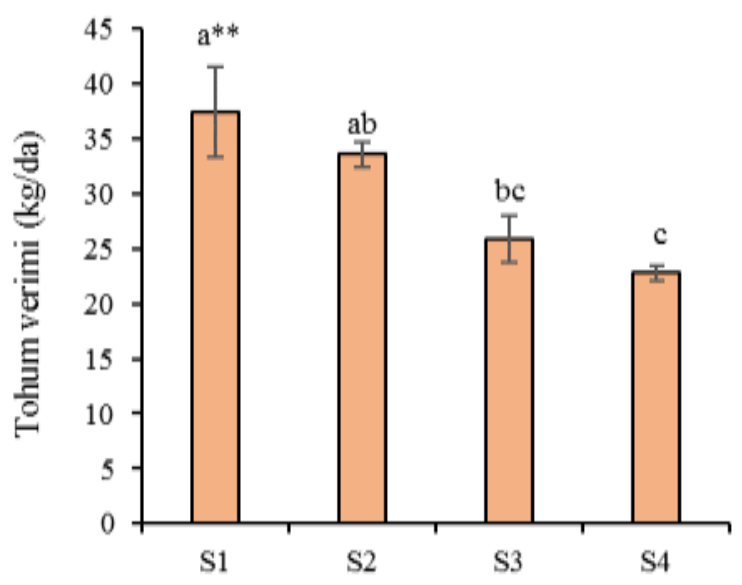

Şekil 3. Farklı sulama miktarlarının rezene bitkisinde tohum verimi üzerine etkileri. ** \%1 seviyesinde önemlidir. Figure 3. Effect of different irrigation levels on the seed yield of fennel plant. ** Significant at the 0.01 level.

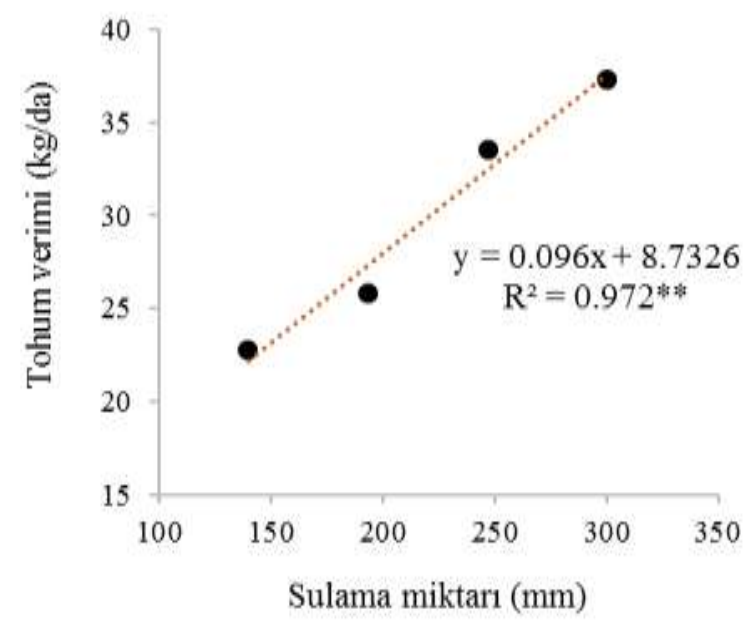

Şekil 4. Sulama miktarı-tohum verimi ilişkisi. ** \%1 seviyesinde önemlidir.

Figure 4. Relationship between irrigation quantities and seed yield. ** Significant at the 0.01 level.

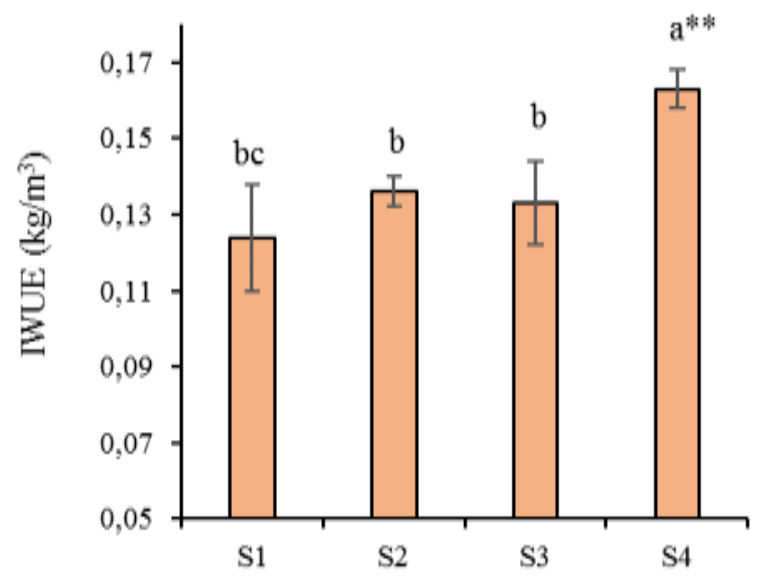

Şekil 5. Farklı sulama miktarlarında sulama suyu kullanım etkinliği (IWUE). **\%1 seviyesinde önemlidir. Figure 5. Irrigation water use efficiency in different irrigation level. **Significant at the 0.01 level. 

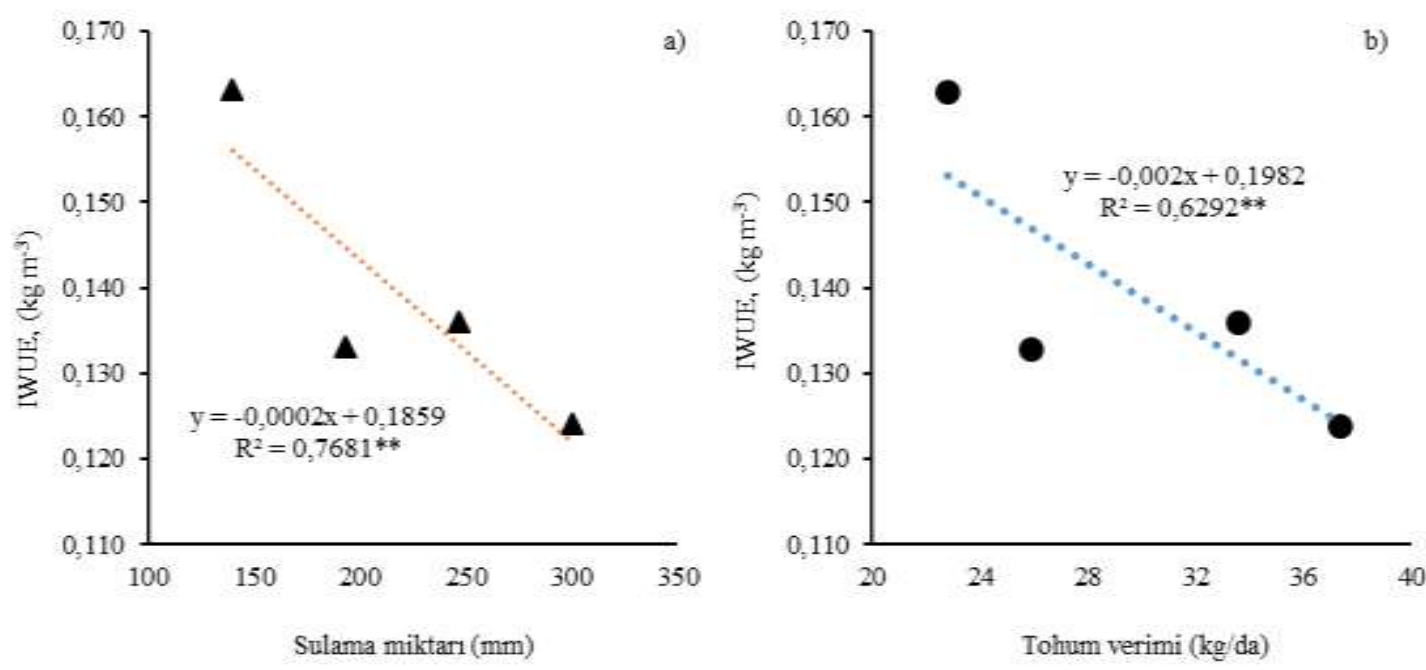

Şekil 6. Sulama suyu kullanım etkinliği ile a) sulama miktarı b) tohum verimi $\left(\mathrm{kg} \mathrm{da}^{-1}\right)$ arasındaki ilişkiler. **\%1 seviyesinde önemlidir. Figure 6. Relationship between irrigation water use efficiency and a) irrigation quantities b) seed yield. ${ }^{* *}$ Significant at the 0.01 level.

\section{Sonuç}

Deneme sonuçları incelendiğinde sulama suyunun uygulanma oranlarına bağlı olarak verim değerleri beklenildiği üzere azalmıştır. Bu bağlamda A sınıfı kaptan olan buharlaşma miktarının tamamının $(\mathrm{Kcp}=1)$ dikkate alınması durumunda verim en yüksek olmuştur. Ancak kurak ve yarı kurak iklim bölgelerinin hâkim olduğu ülkemizde giderek bitki yetiştiriciliğinde kısıtlı sulama koşulları hâkim olmaktadır. Bu çalışma ile rezene bitkisinin hangi sulama seviyesine kadar ekonomik üretiminin sürdürüleceğini belirlemek adına sonuçlar değerlendirilmiştir. Deneme sonuçlarına bakıldığında en fazla sulamanın yapıldığ $\mathrm{S}_{1}$ uygulamasında $\% 60$ oranında kısitl sulama yapılan $\mathrm{S}_{4}$ uygulamasına göre sulama suyunun etkin kullanımı açısından yaklaşı $\% 53.4$ oranında bir tasarruf sağlamıştır. Bunun yanı sıra tohum verimi \%38.9 oranında bir azalma göstermiştir. Ancak sulama miktarındaki daha fazla azalma tohum verimi açısından en yüksek sulama suyu kullanım etkinliği (IWUE) değerlerinin elde edilmesini sağlamıştır. Yetiştiricilik yapılan bölgedeki sulama masrafları ve su miktarı göz önüne alındığında bu verim azalması sulama kullanım etkinliğindeki artış ile beraber değerlendirildiğinde ülkemizde pek çok bölgede tercih edilebilecek bir sonuç ortaya çıkmaktadır. Bu bağlamda değerlendirildiğinde sulama suyu miktarının kısıt konuları belirlenirken bitkinin strese karşı verdiği verim tepkileri ile sulama uygulamalarının gerek iş gücü gerekse ekonomik parametreleri değerlendirilerek uygun bir kombinasyonla en ekonomik seçeneğin oluşturulması gerekmektedir.

\section{Kaynaklar}

Aliabadi FH, Lebaschi MH, Hamidi A (2008) Effects of arbuscular mycorrhizal fungi, phosphorus and water stress on quantity and quality characteristics of coriander. Advances in Natural and Applied Sciences 2(2): 55-59.

Allen RG, Pereira LS, Raes D, Smith M (1998) Crop Evapotranspiration: Guidelines for Computing Crop Water Requirements. Irrigation and Drainage Paper 56, FAO, Rome, Italy.

Aloghareh RR, Tahmasebi BK, Safari A, Armand R, Odivi AG (2013) Changes in essential oil content and yield components of anise (Pimpinella anisum L.) under different irrigation regimes.
International Journal of Agriculture and Crop Sciences 6(7): 364369.

Anonymous (2016) Türkiye' de Sulanan Bitkilerin Su Tüketimi Rehberi. Tarımsal Araştırmalar ve Politikalar Genel Müdürlüğü, Ankara.

Angeli KP, Delazari FT, Nick C, Ferreria MG, da Silva DJ (2016) Yield components and water use efficiency in coriander under irrigation and nitrogen fertilization. Revista Brasileira de Engenharia Agrícola e Ambiental 20(5): 415-420.

Arabacı O, Bayram E (2005) Rezenede (Foeniculum vulgare Mill.) Farklı Ekim Zamanı ve Tohumluk Miktarının Verim ve Bazı Önemli Özellikler Üzerine Etkisi. Türkiye VI. Tarla Bitkileri Kongresi, Antalya, s. 529-534.

Askari E, Ehsanzadeh P (2015) Drought stress mitigation by foliar application of salicylic acid and their interactive effects on physiological characteristics of fennel (Foeniculum vulgare Mill.) genotypes. Acta Physiologiae Plantarum 37(2): 4.

Bahreininejad B, Razmjoo J, Mirza M (2014) Effect of water stress on productivity and essential oil content and composition of Thymus carmanicus. Journal of Essential Oil Bearing Plants 17(5): 717-725.

Bettaieb I, Zakhama N, Wannes WA, Kchouk ME, Marzouk B (2009) Water deficit effects on Salvia officinalis fatty acids and essential oils composition. Scientia Horticulturae 120(2): 271-275.

Bettaieb I, Knioua S, Hamrouni I, Limam F, Marzouk B (2011) Waterdeficit impact on fatty acid and essential oil composition and antioxidant activities of cumin (Cuminum cyminum L.) aerial parts. Journal of Agricultural and Food Chemistry 59(1): 328-334.

Chiyaneh ER, Salmasi SZ, Golezani KG, Delazar, A (2016) Physiological responses of fennel (Foeniculum vulgare $\mathrm{L}$.) to water limitation. Būm/shināsī-i kishāvarzī 4:347-355.

Damjanović B, Lepojević Ž, Živković V, Tolić A (2005) Extraction of fennel (Foeniculum vulgare Mill.) seeds with supercritical CO 2: comparison with hydrodistillation. Food Chemistry 92(1): 143-49.

El Balla MMA, Hamid AA, Abdelmageed AHA (2013) Effects of time of water stress on flowering, seed yield and seed quality of common onion (Allium cepa L.) under the arid tropical Conditions of Sudan. Agricultural Water Management 121: 149-157.

Ertek A (2011) Importance of pan evaporation for irrigation scheduling and proper use of crop-pan coefficient (Kcp), crop coefficient (Kc) and pan coefficient (Kp). African Journal of Agricultural Research, 6(32): 6706-6718. 
Fereres E, Soriano MA (2007) Deficit irrigation for reducing agricultural water use. Journal of Experimental Botany 58: 147159.

Flexas J, Niinemets Ü, Gallé A, Barbour MM, Centritto M, Diaz-Espejo A, Douthe C, Galmés J, Ribas-Carbo M, Rodriguez PL, Rosselló F (2013) Diffusional conductances to CO 2 as a target for increasing photosynthesis and photosynthetic water-use efficiency. Photosynthesis Research 117(1-3): 45-59.

Godara SR, Verma IM, Gaur JK, Bairwa S, Yadav PK (2013) Effect of different levels of drip irrigation along with various fertigation levels on growth, yield and water use efficiency in fennel (Foeniculum vulgare Mill.). The Asian Journal of Horticulture 8: 758-762.

Hasanuzzaman M, Nahar K, Fujita M (2013) Extreme temperature responses, oxidative stress and antioxidant defense in plants. In: Abiotic Stress-Plant Responses and Applications in Agriculture, K. Vahdati and C, Leslie (eds.). InTech. 169-205.

Hassan FAS, Ali EF (2014) Impact of different water regimes based on class-A pan on growth, yield and oil content of Coriandrum sativum L. plant. Journal of the Saudi Society of Agricultural Sciences 13(2): 155-161.

Hassanpour H, Khavari-Nejad RA, Niknam V, Razavi K, Najafi F (2014) Effect of penconazole and drought stress on the essential oil composition and gene expression of Mentha pulegium L.(Lamiaceae) at flowering stage. Acta Physiologiae Plantarum 36(5): 1167-1175.

Howell T (2001) Enhancing water use efficiency in irrigated agriculture. Agronomy Journal 93(2): 281-289.

Jat ML, Shivran AC, Puniya MM, Boori PK, Ola BL, Verma HP (2015) Effect of drip irrigation scheduling on growth and seed production of fennel (Foeniculum vulgare Mill.) under semi-arid agro-climatic condition International J. Seed Spices 5(2): 67-73.

Karaca A (1998) Kișniş (Coriandrum sativum L.) ve Rezene (Foeniculum vulgare Mill.) Bitkilerinde Fenolojik, Morfolojik ve Bazı Teknik Özellikler Üzerinde Çalışmalar. Yüksek Lisans Tezi, Ondokuz Mayıs Üniversitesi Fen Bilimleri Enstitüsü, Samsun.

Kaur GJ, Arora DS (2010) Bioactive potential of Anethum graveolens, Foeniculum vulgare and Trachyspermum ammi belonging to the family Umbelliferae-Current status. Journal of Medicinal Plants Research 4(2): 087-094.

Klute A (1986) Methods of Soil Analysis: Physical and Mineralogical Properties. Part I, Second Edition. ASA- SSSA Agronomy No: 9, Madison, WI.

Nik ZB, Mirza M, Ghaffari M (2008) Effect of drought stress on growth and essential oil contents in Parthenium argentatum Gray. Journal of Essential Oil Bearing Plants 11(4): 423-429.

Nourimand M, Mohsenzadeh S, da Silva JAT (2012) Physiological responses of fennel seedling to four environmental stresses. Iranian Journal of Science \& Technology A1: 37-46.

Meena M, Sagarka BK, Das T, Poonia TC (2016) Effect of drip irrigation and nitrogen levels on growth parameters and yield of drilled rabi fennel (Foeniculum vulgare Mill) in Saurashtra region of Gujarat. Res. Environ. Life Sci 9(1):97-99.

Miraldi E (1999) Comparison of the essential oils from ten Foeniculum vulgare Miller. samples of fruits of different origin. Flavour and Fragrance Journal 14(6): 379-382.

Mirzaei A, Naseri R, Moghadam A, Esmailpour-Jahromi M (2013) The effects of drought stress on seed yield and some agronomic traits of canola cultivars at different growth stages. Bulletin Environmental Pharmacology Life Science 2: 115-121.

Ozturk A, Unlukara A, Ipek A, Gurbuz B (2004) Effects of salt stress and water deficit on plant growth and essential oil content of lemon balm (Melissa officinalis L.). Pakistan Journal of Botany 36(4): 787-792.

Özkan F (1999) Tatlı Rezenede Bitki Sıklığının Verim ve Verim Öğeleri Üzerine Etkileri. Yüksek Lisans Tezi, Ankara Üniversitesi Fen Bilimleri Enstitüsü, Ankara.

Page AL, Miller RH, Keeney DR (1982) Methods of Soil Analysis: Chemical and Microbiological Properties. Part II, Second Edition. ASA-SSSA Agronomy No: 9, Madison, WI.

Seghatoleslami M (2013) Effect of water stress, bio-fertilizer and manure on seed and essential oil yield and some morphological traits of cumin. Bulgarian Journal of Agricultural Science 19(6): 1268-1274.

Semiz GD, Ünlükara A, Yurtseven E, Suarez DL, Telci İ (2012) Salinity impact on yield, water use, mineral and essential oil content of fennel (Foeniculum vulgare Mill.). Tarım Bilimleri Dergisi - Journal of Agricultural Sciences 18: 177-186.

Shiranirad AH, Zandi P (2012) The effect of drought stress on qualitative and quantitative traits of spring rapeseed (Brassica napus L.) cultivars. Agriculture 99: 47-54.

Soil Survey Staff (1992) Keys to Soil Taxonomi. Fifth Edition. SMSS Technical Monograph No: 19, Pocahontas Pres. Inc., Blacksburg.

Solanki RM, Vasava MS, Gohil BS (2017) Influence of drip irrigation and fertility levels on growth, yield and water use efficiency of drilled rabi fennel (Foeniculum Vulgare Mill.). International Journal of Science, Environment and Technology 6(3): 1972-1978.

White DH, Howden SM (2010) Climate and its effects on crop productivity and management. In: Soils, Plant Growth and Crop Production, Vol-I, W.H. Verheye (ed.). EOLSS Publishers Co Ltd. pp. 44-78.

Zardak SG, Dehnavi MM, Salehi A, Gholamhoseini M (2016) Responses of field grown fennel (Foeniculum vulgare Mill.) to different mycorrhiza species under varying intensities of drought stress. Journal of Applied Research on Medicinal and Aromatic Plants 5: 16-25.

Zhou S, Duursma RA, Medlyn BE, Kelly JW, Prentice IC (2013) How should we model plant responses to drought? An analysis of stomatal and non-stomatal responses to water stress. Agricultural and Forest Meteorology 182: 204-214. 